\title{
External Mentoring Support for Early Career Special Education Teachers
}

Ian Dempsey and Judith Christenson-Foggett

University of Newcastle, Australia

\begin{abstract}
$T$ he special education teaching profession has experienced longstanding problems with shortages of qualified teaching staff and with high turnover rates of these staff. A variety of issues are related to these problems, including the nature of the support that early career special education teachers receive. In this case study research, the use of external mentoring support to two early career special education teachers in their first year of teaching was examined. This mentoring support was provided by an experienced special educator who did not work at the teachers' schools. The results suggest that external forms of mentoring support may offer important advantages over traditional, sitebased forms of support.
\end{abstract}

Keywords: mentoring, early career teachers, special education teachers

Teaching is a significant occupational profession comprising around $4 \%$ of the workforce in many developed countries (Nickson \& Kritsonis, 2006). However, the profession faces chronic difficulties with a high turnover of early career teachers, and an ageing teaching workforce with impending large numbers of retirements (Lauder, 2008). Explanations to why attrition occurs include a lack of effective preparation in preservice courses, stress from lack of time to develop effective and consistent instructional approaches, and a lack of support during induction programs at individual schools (Liston, Whitcomb, \& Borko, 2006).

In special education the situation for teachers is especially challenging. For some time, the literature has noted significant problems with special education teacher attrition and retention (Billingsley, 1993; Billingsley, Carlson, \& Klein, 2004) in both regular school and special school settings (Talmor, Reiter, \& Feigin, 2005). For example, a survey distributed to Victorian public special schools in 2006 suggest that that there will be a serious depletion of qualified special education teachers, with $45 \%$ of staff being aged over 50. There is a persistent shortage of qualified special education teachers (Nickson \& Kritsonis, 2006), and one quarter of new teaching graduates will leave the profession within five years (Kelly, 2008). Special education teachers are more likely to move from special education or to leave teaching than other teachers (Cochran-Smith, 2004; Ingersoll, 2001; McLesky \& Billingsly, 2008), and some studies show that the turnover rate for special education teachers is one and a half times that of regular education teachers (Miller, McKenna, \& McKenna, 1998). Attrition of this scale

Note: This manuscript was accepted under the editorship of Jennifer Stephenson.

Address for correspondence: Ian Dempsey, Centre for Special Education and Disability Studies, School of Education, University of Newcastle, Callaghan, NSW 2308, Australia.

E-mail: Ian.Dempsey@newcastle.edu.au 
exacerbates an already serious problem of a shortage of teachers qualified to fill special education positions. There are significant costs associated with this attrition. Norton (1999) estimated that replacing a teacher costs $25 \%$ of that person's annual salary. This is a high cost for systems but the higher cost is paid by those students with special needs who lose the opportunity to receive instruction from qualified and experienced staff.

Several interrelated factors are associated with teacher retention. These include external factors (e.g., teacher preparation), employment factors (e.g., working conditions and rewards), and personal factors (Boyer, 1999). Consequently, mentoring (an employment factor) is just one factor influencing a special educator's decision to stay in the field. In a US study of three university-school district partnership programs that supported induction of beginning special educators, it was concluded that the induction and mentoring aspects of training needs to move beyond the boundaries of the university and into the early years of teaching in the classroom (Boyer, 2005). Nevertheless, mentoring, along with access to curriculum resources and cooperative planning, is one of the most highly valued support strategies reported by early career teachers (Department of Education, Science and Training [DEST], 2002). Mentoring has received substantial practical and policy attention in recent years across general school education systems following evidence that the experience of the first year of teaching is crucial to teachers' future in the profession (Wasburn-Moses, 2005). Consequently, mentoring is best viewed as an essential component of a teacher's induction program which begins with preservice education and extends into the teacher's early career.

Early career teachers value mentoring support that meets their immediate planning needs, which provides personal support, and which is ongoing (Boyer \& Gillespie, 2000). Mentoring in the first years of teaching typically moves through a series of stages (Whitaker, 2000). Early stages may be best described as 'survival', focus on the beginning teacher, and include emotional support, meeting procedural requirements, behaviour management and the development of teaching programs. Later stages concentrate more on teaching processes, the learning outcomes of students and forms of external support such as networking with relevant professionals.

Despite increased attention on mentoring, it has been subjected to very little evaluation. Griffin, Winn, Otis-Wilborn, and Kilgore (2003) reviewed 10 US studies of special education teacher induction (many including mentoring) conducted between 1991 and 2001. The results of these studies demonstrate high satisfaction with mentoring, improvements in perceptions of self-confidence and collaboration, and intentions to remain in teaching for the next five years by early career special educators. The perceived effectiveness of mentoring was significantly correlated with intention to remain in special education (Whitaker, 2000). However, Andrews and Quinn (2005) found that the quality and quantity of mentor support varied widely in the United States. In Australia, although the states and territories have policies on the induction of early career teachers, induction is seen as primarily a school responsibility and there is considerable variation across and within states in the implementation of induction programs. Further, over one third of Australian early career teachers were either dissatisfied with the induction they received or they received no induction at all (DEST, 2002).

The growing literature on teacher mentoring suggests diverse purposes and models of delivery. Certainly, it is not possible to generalise about any one dominant method given the heterogeneous program descriptions in the literature. Examples of reported mentoring approaches are: 
- face-to-face interaction away from class

- scheduled whole group meetings

- phone follow-up

- online forums or discussion groups

- in-class modelling.

Conderman and Stephens (2000) noted that 'successful mentoring programs encourage the development of a relationship between mentor and mentee while providing assistance tailored to the needs and challenges of the beginning teacher' $(2000, \mathrm{p}$. 17). The importance of a flexible approach that builds on a positive and empathetic relationship is a theme that is repeated in much of the literature.

Mentoring models have become more complex and flexible with the growth of online communication technologies. Online technologies allow mentoring relationships to be created from a much larger pool of participants than traditional forms of mentoring (DeWert, Babinski, \& Jones, 2003; Paulus \& Scherff, 2008). Such technologies can reduce the pressures of close scrutiny on beginning teachers at their school site, allowing a degree of anonymity in the mentoring process, and they can allow teachers to participate in mentoring activities at times that suit them. Australian research conducted by Schuck, Segal, Anderson, and Balding (2000) found that new teachers prefer support from 'experienced practitioners outside their own school' (Schuck \& Brady, 2005, p. 65), and that online learning has potential benefits in professional development and induction.

Online mentoring is also potentially less expensive (in terms of time and travel) than some face-to-face mentoring programs (Gareis \& Nussbaum-Beach, 2007; Gentry, Denton, \& Kurz, 2008). A further important consideration is the appointment of mentors. The use of mentors from staff at the early career teacher's school may create tensions between assessment and assistance and will result in the selection of mentors from a limited skill pool. Many beginning teachers complete a probationary period in their first years of teaching, with full certification dependent on a satisfactory assessment by school supervisors. Thus, it is not surprising that many early career teachers express a reluctance to be open with mentors whose evaluations may contribute to probation decisions (DEST, 2002).

There are very few examples of mentors being provided from outside of the early career teacher's school (e.g., from the district level). This is surprising, given that this mentoring support model reduces the likelihood of conflict of interest and can overcome the competing demands experienced by mentors. Although the research is quite limited, some findings offer potential in the design of innovative models of mentoring support in special education (Andrews \& Quinn, 2005). These findings suggest that the use of externally appointed mentors with demonstrated special education teaching expertise and offering online support are likely to offer important advantages over school-based mentoring support.

The present study sought to advance our understanding of mentoring support for early career special education teachers by examining the use of an externally appointed mentor in an Australian school system. The research questions for this study were:

1. How do early career special education teachers make use of external mentoring support and what benefits (if any) do they perceive in such support?

2. How does the nature of external mentor support change over time and how does it interact with site-based and other forms of support for early career special education teachers? 


\section{Methodology}

\section{Participants}

The participant pool comprised all graduates from the 2007 cohort of students completing the special education specialisation as part of their undergraduate teaching program at the University of Newcastle, Australia. This specialisation was undertaken in the final year of the graduates' program and provided a special education qualification recognised by Australian education providers. At the end of 2007, graduates were asked to provide their personal email contact details to the program convenor to assist in University quality assurance activity.

Twenty-seven graduates provided their contact details and nine graduates responded to a mid-2008 request to participate in the study. Two of these graduates met the requirements for participation in the study (i.e., they were working full-time in special education teaching positions in NSW public schools, and they also agreed to participate in the 9-month research project). Both early career teachers, Lisa and Kathryn (pseudonyms) had been appointed to their current teaching positions at the beginning of the 2008 school year and both taught in a support class in regular primary schools.

\section{Research Protocol}

The project received ethics clearance from the University of Newcastle, and clearance from the NSW Department of Education and Training, which provides public school education and is a significant provider of special education services. NSW is one of Australia's six states and had a population of 6.9 million in 2007 (Australian Bureau of Statistics, 2008).

All graduates who provided their contact details were emailed an invitation package in August 2008 that comprised an information letter and consent to participate. Consent to participate meant participating in a 1-hour interview with an external mentor, permitting a half-day observation of their classroom, and agreeing to maintain regular email and/or phone contact with the external mentor.

For the two participants, information letters and consent forms were also sent to their school principals and a colleague teacher (CT) that the early career teacher worked closely with. Consent to participate for the principal and CT meant permitting the study to proceed at the school and completing a 1-hour interview at the start and the end of the project.

Structured interviews were conducted with all participants in October 2008 and in June 2009. For early career teachers, interview questions requested details on their satisfaction with teaching, the teaching issues they regarded as important, the adequacy of formal and informal supports available to them, and their intention to remain in the profession. For principals and CTs, interview questions addressed their impressions of how well the early career teacher had transitioned to teaching, the teacher's professional skills, and a discussion of formal and informal support provided to the early career teacher.

The external mentor and second author of this article was a regular and special education teacher with over 28 years teaching experience, as well as recent experience as a university special education lecturer. The external mentor was known by both the early career teachers who participated. A half-day training program was provided to the mentor that included the reading and discussion of recent research on mentoring early career teachers (Conderman \& Stephens, 2000; Department of Education, Science \& Training, 2002; Whitaker, 2000), as well as an explanation of the research procedures to be used for this project. In particular, the likely professional needs of early career special education teachers, resources that may be helpful to such teachers, and the use of face-to-face 
discussion and email exchange as means of communication were discussed. Throughout the duration of the research, the principal author maintained regular contact with the external mentor to review progress.

\section{Data Analysis}

This research follows a case study design that used mixed methods of data collection including interviews, email documents, document analysis and classroom observation, although the interviews and email documents were the dominant means of data collection (Yin, 2003). Visits to the schools, interviews, and ongoing contact with early career teachers were conducted by the external mentor. Interviews were not taped; the mentor collected detailed notes at the time of interview. Examination of the interview and email data was completed using content analysis that is used to reduce large amounts of data into manageable themes (Babbie, 2001). This process of data reduction involves the coding of data into appropriate themes that develop from early data analysis and is refined as that analysis continues (Boyatzis, 1998, p. 4). To enhance the validity of the findings, participants at each school were given a written description of the principal themes emerging from the first round of interviews, and they were given the opportunity to edit those themes. None of the participants chose to make changes to these descriptions.

\section{Results}

\section{School A}

School A was located in Sydney, in a middle-class area with little public housing. The regular primary school enrolled 580 students and had two longstanding gifted and talented classes. There were a high proportion of non-English speaking background students (45\%), of whom the majority were of Asian background. The principal had recently been appointed to the school, while other staff had been at the school for some time. There were two classes for students with a disability at the school; one was a class for students with moderate intellectual disability, the other (Lisa's class) was for students with autism.

Lisa was in her mid-20s and was a targeted graduate (i.e., following an interview selection process in mid-2007 with the NSW Department of Education and Training she was guaranteed a position from the beginning of 2008). Her class comprised seven students with autism, with a wide range of abilities and ages. She had access to a full-time teacher's aide. Several students in her class displayed aggressive and other challenging behaviour. There were limited opportunities for the inclusion of Lisa's students in regular school activities. Lisa's teaching environment was a standard classroom located among mainstream classes.

The school principal and CT spoke very positively of Lisa's capability; her organisation, use of resources, knowledge of the individual planning process and the needs of students with autism were noted. As there had been a high turnover of teaching staff on this class, both the principal and CT were anxious to support Lisa as much as possible to ensure some continuity for both herself and her students. There were some initial concerns by the principal about Lisa's use of voice, which dissipated after she followed advice. While the principal (Lisa's supervisor) and Lisa's special education teacher colleague (her in-school mentor) were very happy with her progress, they admitted that they knew little about special education.

Lisa felt that her first months of teaching were difficult, that her prepared resources were not useful, and that at times the job seemed overwhelming. Lisa had no working knowledge of the structure of the class and little was known about the students transitioning into the 
class at the start of the year. A death in her family and difficulties with finding personal accommodation contributed to Lisa's concerns. She said that the personal support of the $\mathrm{CT}$, and the knowledge of class routines by the teacher's aide was crucial in helping her get through that difficult time. At the time of her first interview, Lisa was adamant that she would still be teaching in 5 years time, but was uncertain whether she would be working in special education.

\section{School B}

School B was in a small town in rural NSW, with a population of about 5000, and was about a 45-minute drive from the nearest regional centre. Total school enrolment was 320 students. The student population included students of Aboriginal background, and students from mixed socioeconomic environments. Kathryn's was the only class for students with a disability in the regular primary school. Her class of five students with moderate and severe intellectual disability had the use of a full-time teacher's aide. The principal had been at the school for 3 years and there was a mixture of newer and older, mostly female, teaching staff at the school. None of the staff at the school had qualifications or teaching experience in special education.

Kathryn was in her mid-20s. Her class included three students with autism, one student with physical and intellectual disability, and one student with an undiagnosed developmental disability. One of the students lived in the town while the others were bused or taxied to and from the school. One of Kathryn's students displayed severe behaviour problems. She taught in a large demountable classroom that was separated from the mainstream classes. The classroom had its own fenced playground, a change and storage area and a toilet. There was minimal inclusion of Kathryn's students in wider school activities; however, Kathryn was keen to expand inclusion opportunities.

Both the principal and CT were impressed by Kathryn's calm and professional manner, highlighted her excellent understanding of curriculum and programming, her organisation and ability to relate well to the teacher's aide, and her proactive development of resources and programs. The school had experienced difficulty in appropriate staffing of Kathryn's class and went to some lengths after Kathryn arrived to provide her with release days for meeting students' families and other support activities.

As her class presented with many disabilities and with behaviour problems, after arriving Kathryn focused on establishing routines and social skills for her students. Later, she expressed frustration with a lack of responsiveness by district staff for requests for assistance in accessing therapy services and background information on the characteristics and needs of her students.

Kathryn felt that other teachers at the school expected her to be an expert on special education issues and that she felt she needed to talk to other special education teachers about her concerns. Due to the relative isolation of her school and the lack of opportunity for her to visit other special education settings, she could only have phone contact with the closest special education school. Kathryn believed she needed continuing opportunities to see how other special education staff were working with similar students.

Kathryn saw herself as teaching in 5 years time, but not necessarily in special education. She wanted some experience with teaching mainstream classes. This desire was supported by the principal, saying he would like her to move on after 5 years to ensure that she does not 'burn out'. 


\section{E-mail Discussion Themes}

During the first visit to the schools, the external mentor gave both early career teachers the opportunity to select the nature and frequency of ongoing contact. Both teachers opted for weekly e-mail contact for the remainder of the year. Examples of the support provided by the external mentor during e-mail contact were:

- specific teaching resources (e.g., use of visual learning strategies, outcomes-based lessons)

- advice on behaviour support strategies (e.g., different theoretical approaches to managing behaviour, diet/nutrition and behaviour)

- emotional support (e.g., reassurance that the early career teacher was doing well, suggestions on ways to reduce personal stress)

- advice on support structures in the public school system.

There were some differences in the nature of the e-mail exchanges for each of the teachers. During the first months, Lisa sought advice on behaviour management for the whole class and for specific students. One student in her class with serious behaviour problems dominated exchanges. Other, but much less frequent exchanges related to suggestions on reporting students' results and curriculum planning. Later in the intervention, Lisa requested advice on programming support. She maintained sporadic contact with the mentor in the final 6 months of the project that prompted a phone call by the external mentor. It transpired that Lisa had been ill and away from school for a short period and there had been a critical incident at the school involving the student in her class with challenging behaviour. The student had physically attacked her and he was subsequently removed from the school. The experience was quite stressful for Lisa, although counselling was provided by her employer and there was support from school staff. Although this early career teacher appreciated the support provided by her external mentor, she explained that time demands prevented her from maintaining more regular contact and she provided little feedback on whether the mentor's suggestions were implemented in her classroom or were successful.

Initial e-mails from Kathryn provided comprehensive information on all individual students in her class, often with detailed descriptions of their social skills and behaviour. She showed proficiency with program and curriculum development, with the support of her school colleagues. Kathryn sought no assistance from the external mentor for these aspects of her work. Weekly contact was maintained during 2008; this dropped off to contact every 2 to 3 weeks in the final 6 months of the intervention. Most of her later emails were dominated by two new kindergarten enrolments in her class. One of these students presented with challenging behaviours and the other student was described as having borderline mild/moderate intellectual disability. Kathryn was able to use advice from the external mentor to meet the needs for the student with challenging behaviours but was more concerned with the second student. This student was relatively high functioning in her class and Kathryn felt that she couldn't offer him the programs that he needed to be successful in mainstream classes. The external mentor provided advice on this including sample programs and by the end of the project this student had been mainstreamed. Kathryn gave regular feedback to the external mentor on the effectiveness of the resources and teaching strategies provided to her.

\section{Second Interview Themes}

A return visit to both schools was completed by the external mentor in June 2009 when all participants were re-interviewed. There were some similarities in the conclusions of 
all participants across the schools. All believed that the external mentor should have a sound working knowledge of the special education classroom, of students with varying disabilities, and a good understanding of the relevant school system. Ideally, the mentor should also have viewed the early career teacher's classroom. The CT and principal from School B believed that more '... special education dialogue ...' was important for the support of early career teachers in rural communities. However, the principal from this school believed that the public school system should be providing this increased support and mentoring opportunities rather than it being dependent upon an external body.

Both early career teachers liked the immediacy of replies from the external mentor as this helped to alleviate some concerns about difficult situations they encountered. However, Lisa stressed that colleague teacher support at the school was most important and that having a colleague in a similar situation (e.g., where there are two or more similar classes in the school) was ideal. While attending a professional development session, Lisa met and developed a relationship with a teacher at a nearby school who was working in a similar situation. She found that this supplemented her relationship with the other special education teacher at her school.

Kathryn, who worked in a rural school, was well supported by her principal and CT. However, neither of them had expertise in special education. She was encouraged to take advantage of training opportunities, but the travel distance and the difficulty of finding casual staff to replace her limited her involvement. There was district support available via visiting special education consultants. However, Kathryn reported that often the district was slow to reply to requests for assistance, sympathised when they visited her, but offered little practical assistance. She found this lack of responsiveness frustrating. The external mentor was able to provide much of the support that the district office was unable to give her.

Having personal trust in the mentor was seen as vital by both Kathryn and Lisa so that questions that may be perceived as being 'silly' ('... knowledge of how to write a spelling program which everyone here seems to know'; Lisa) could be asked without 'being embarrassed ...' (Kathryn). This view was supported by the principal and CT from School A and the CT in School B. Both believed it was important to talk to someone external to the school system so the early career teachers could feel confident in asking basic questions by 'unloading' and alleviating frustrations and stress.

The expectation of regular contact with the external mentor was not perceived as onerous by either early career teacher. Kathryn believed this process made her record in an ordered manner what she was concerned about, what she required assistance with, and what she was trying to achieve. Lisa sometimes found e-mailing time-consuming because of her work demands and did not email as often as she would have liked.

Both Lisa and Kathryn appreciated the samples of programs and resources and the good working knowledge of public school processes by the external mentor. When asked how to improve on the external mentoring system, Kathryn recommended an online chat room or a discussion board approach where there could be ongoing dialogue, including questions from other special education teachers with a mentor to oversee the site. Here, the mentor could provide suggestions or other special education teachers could share their experiences and resources with each other without direct contact with systemic staff. Kathryn and Lisa were still unsure whether they would be teaching in special education settings in 5 years time. Both principals and CTs reinforced that they would like to see the early career teachers move either into another special education setting or into mainstream education after 5 years to reduce the chance of them experiencing 'burn out'. 


\section{Discussion}

This research sought to examine the utility of an external mentoring form of support for early career special education teachers. Specifically, the study asked how do early career special education teachers make use of external mentoring support and what benefits (if any) did they perceive in such support? The study also investigated whether the nature of external mentoring support changed over time and how this type of support interacted with site-based and other forms of support for early career special education teachers.

In relation to the first question, both early career teachers appreciated the provision of external mentoring support, both appreciated how responsive this support was to their individual needs, but both used this support in different ways. Although by the end of the intervention Lisa had established contact with a teacher at a nearby school who was working with students with similar needs to her own, she found the advice of the external mentor helpful. Similarly, Kathryn appreciated the assistance of the external mentor particularly because she worked in an isolated setting.

The results for the second research question were equivocal. Lisa's needs were dominated by the challenging behaviour of the students in her class and these needs did not significantly change over the course of the study. That these needs did not change may have been a function of this challenging behaviour and her difficulty in settling individual students into her class. Programming to enhance student learning, which the literature suggests is an issue that early career teachers transition to after establishing themselves in the classroom (Whitaker, 2000), was not raised by Lisa in her exchanges with the external mentor. However, she used some programming ideas offered by the CT in the other support class. On the other hand, Kathryn's confidence and expressed belief in her ability to program adequately for her students may have permitted her to move beyond behaviour management issues to focus on the individual support needs of her students, including the needs of a student in her class to successfully transition to a regular class.

This study had a number of limitations that need to be acknowledged and may limit the generalisation of the results. First, the external mentor was known to both early career teachers because the mentor had lectured to the teachers while they were completing their teacher training program and this mentor also collected the research data for this project. These relationships may have influenced the participation of the early career teachers in the research and may have influenced interpretation of the data. A second limitation was the relatively brief intervention period of 9 months that did not permit a thorough examination of changes in the support priorities of the early career teachers. In Lisa's case, the characteristics of the students in her class no doubt influenced her requests for advice on behaviour support, but whether the nature of those requests may have shifted to non-behavioural areas if the intervention period had been longer is unclear.

Notwithstanding these limitations, this study demonstrates that external forms of mentoring support for early career special education teachers show good potential for supplementing existing forms of mentoring, and, in some cases, external mentoring may be the most effective form of mentoring for such teachers. In metropolitan areas, both formal and informal means of mentoring support are relatively easy to establish because of the size of schools and the opportunity for networking with staff in similar situations. However, such opportunities do not often exist in rural and remote communities where the special education teacher may be the only teacher at the school with special education expertise and experience and where access to consultancy support from district levels may be limited (Ladd, 2007). 
The experience in Australia is that the quality of in-school mentoring is a hit or miss affair (Department of Education, Science \& Training, 2002). No doubt in-school mentoring offers important cost advantages over other supports for early career teachers. Nevertheless, that in-school mentors may not always volunteer for this position, that they may not have the specific expertise required, that they are expected to 'juggle' their mentoring responsibility within their existing workload, and that their role as a mentor may compromise any role they may have in decisions on the certification of the early career teacher demonstrates that there can be significant problems with this model of mentoring (Carter, 2000; Stephens \& Moskowitz, 1997).

The establishment and maintenance of external mentors by educational authorities, or the deployment of existing special education consultants in an external mentoring mode, may require the allocation of some additional resources by educational authorities. Nevertheless, given the chronic difficulties in attracting and retaining suitably qualified special education teachers, such an allocation of resources may offer significant advantages for the longevity of those special education teachers' careers and for the educational outcomes of the students those teachers support.

\section{References}

Andrews, B.D., \& Quinn, R.J. (2005). The effects of mentoring on first-year teachers perceptions or support received. The Clearing House, 78, 110-116.

Australian Bureau of Statistics. (2008). NSW state and regional indicators, Dec 2008. Retrieved on June 2, 2009 from http://www.abs.gov.au/

Babbie, E. (2001). The practice of social research. Belmont, CA: Wadsworth.

Billingsley, B.S. (1993). Teacher retention and attrition in special and general education: A critical review of the literature. Journal of Special Education, 27, 137-174.

Billingsley, B., Carlson, E., \& Klein, S. (2004). The working conditions and induction support of early career educators. Exceptional Children, 70, 333-347.

Boyatzis, R.E. (1998). Transforming qualitative information. Thousand Oaks, CA: Sage.

Boyer, K.L.W. (1999). A qualitative analysis of the impact of mentorships on new special educators' decisions to remain in the field of special education (ERIC Document Reproduction Service No. ED438643). Washington, DC: Education Resources Information Centre.

Boyer, L. (2005). Supporting the induction of special educators: Program descriptions of universityschool district partnerships. Teaching Exceptional Children, 37(3), 44-52.

Boyer, L., \& Gillespie, P. (2000). Keeping the committed: The importance of induction and support programs for new special educators. Teaching Exceptional Children, 33(1), 10-15.

Brady, L., \& Schuck, S. (2005). Online mentoring for the induction of beginning teachers. Journal of Educational Enquiry, 6(1), 65-75.

Carter, M. (2000). Mentoring and teacher professional learning: A review of the literature and an exploration of mentoring practices (Initial and Continuing Teacher Development Occasional Paper No 3, Training and Development Directorate). Sydney, Australia: NSW Department of Education and Training, Sydney.

Cochran-Smith, M. (2004). Stayers, leavers, lovers, and dreamers: Insights about teacher retention. Journal of Teacher Education, 55, 387-392.

Conderman, G., \& Stephens, J.T. (2000). Voices from the field: Reflections from beginning special educators. Teaching Exceptional Children, 33(1), 16-21.

Department of Education, Science, and Training (DEST). (2002). An ethic of care: Effective programmes for beginning teachers. Canberra, Australia: Author.

DeWert, M.H., Babinski, L.M., \& Jones, B.D. (2003). Safe passages: Providing online support to beginning teachers. Journal of Teacher Education, 54, 311-320.

Gareis, C.R., \& Nussbaum-Beach, S. (2007). Electronically mentoring to develop accomplished professional teachers. Journal of Personnel Evaluation in Education, 20, 227-246. 
Gentry, L.B., Denton, C.A., \& Kurz, T. (2008). Technologically-based mentoring provided to teachers: A synthesis of the literature. Journal of Technology and Teacher Education, 16, 339-373.

Griffin, C.C., Winn, J.A., Otis-Wilborn, A., \& Kilgore, K.L. (2003). New teacher induction in special education. Gainsville, FL: Centre on Personnel Studies in Special Education, University of Florida.

Ingersoll, R.M. (2001). Teacher turnover, teacher shortages, and the organization of schools. Retrieved on February 19, 2008 from http://depts.washington.edu/ctpmail/PDFs/Turnover-Ing-01-2001.pdf

Kelly, M. (2008, January 11). Hard lessons: Why one in four new Hunter teachers will quit. Newcastle Herald, p. 1.

Ladd, H.F. (2007). Teacher labour markets in developed countries. The Future of Children, 17, $201-217$.

Lauder, S. (2008). Teacher shortage needs urgent attention, survey shows. Retrieved on January 30, 2008 from http://www.abc.net.au/news/stories/2008/01/16/2139571.htm

Liston, D., Whitcomb, J., \& Borko, H. (2006). Too little or too much: Teacher preparation and the first years of teaching. Journal of Teacher Education, 57, 351-358.

McLeskey, J., \& Billingsley, B.S. (2008). How does the quality and stability of the teaching force influence the research-to-practice gap? A perspective on the teacher shortage in special education. Remedial and Special Education, 29, 293-306.

Miller, J.W., McKenna, M.C., \& McKenna, B.A. (1998). A comparison of alternatively and traditionally prepared teachers. Journal of Teacher Education, 49, 165-176.

Nickson, L.M., \& Kritsonis, W.A. (2006). A national perspective: An analysis of factors that influence special educators to remain in the field of education. Doctoral Forum, 1, 1-5.

Norton, M.S. (1999). Teacher retention: Reducing costly teacher turnover. Contemporary Education, $70(3), 52-55$.

Paulus, T., \& Scherff, L. (2008). 'Can anyone offer any words of encouragement?' Online dialogue as a support mechanism for preservice teachers. Journal of Technology and Teacher Education, 16(1), $113-136$.

Stephens, M., \& Moskowitz, J. (1997). From students of teaching to teachers of students: Teacher induction around the Pacific rim. Retrieved on March 16, 2010 from http://www.ed.gov/pubs/APEC/

Talmor, R., Reiter, S., \& Feigin, N. (2005). Factors related to regular education teacher burnout in inclusive education. European Journal of Special Needs Education, 20(2), 215-229.

Thomas, T. (2007). The impending special education qualifications crisis. Australasian Journal of Special Education, 31, 139-145.

Thomas, T. (2009). The age and qualifications of special education staff in Australia. Australasian Journal of Special Education, 33, 109-116.

Wasburn-Moses, L. (2005). How to keep your special education teachers. Principal Leadership, 5(5), 35-38.

Whitaker, S.D. (2000). Mentoring beginning special education teachers and the relationship to attrition. Exceptional Children, 66, 546-566.

Yin, R.K. (2003). Case study research: Design and methods (3rd ed.). London: Sage. 